\title{
Preferred temperature and thermal breadth of birds wintering in peninsular Spain - limited effect of temperature on species distribution
}

Luis M. Carrascal, Sara Villén-Pérez, David Palomino

Background. Availability of environmental energy, as measured by temperature, is expected to limit the abundance and distribution of endotherms wintering at temperate latitudes. A prediction of this hypothesis is that birds should attain their highest abundances in warmer areas. However, there may be a spatial mismatch between species preferred habitats and species preferred temperatures, so some species might end-up wintering in sub-optimal thermal environments. Methods. We model the influence of minimum winter temperature on the relative abundance of 106 terrestrial bird species wintering in peninsular Spain, at $10 \times 10 \mathrm{~km}^{2}$ resolution, using 95\%-quantile regressions. We analyze general trends across species on the shape of the response curves, the environmental preferred temperature (at which the species abundance is maximized), the mean temperature in the area of distribution and the thermal breadth (area under the abundance-temperature curve). Results. Temperature explains a low proportion of variation in abundance. The most significant effect is on limiting the maximum potential abundance of species. Considering this upper-limit response, there is a large interspecific variability on the thermal preferences and specialization of species. Overall, there is a preponderance of positive relationships between species abundance and temperature; on average, species attain their maximum abundances in areas $1.9{ }^{\circ} \mathrm{C}$ warmer than the average temperature available in peninsular Spain. The mean temperature in the area of distribution is lower than the thermal preferences of the species. Discussion. Many species prefer the warmest areas to overwinter, which suggests that temperature imposes important restrictions to birds wintering in the Iberian Peninsula. However, one third of species overwinter in locations colder than their thermal preferences, probably reflecting the interaction between habitat and thermal requirements. There is a high inter-specific variation in the versatility of species using the available thermal space, and the limited effect of temperature highlights the role of other environmental factors determining species abundance. 
1 Preferred temperature and thermal breadth of birds wintering in peninsular 2 Spain - limited effect of temperature on species distribution.

3 Luis M. Carrascal ${ }^{1}$, Sara Villén-Pérez ${ }^{1,2}$, David Palomino ${ }^{2}$

$4{ }^{1}$ Department of Biogeography and Global Change, Museo Nacional de Ciencias Naturales (MNCN-

5 CSIC). Madrid, Spain.

$6 \quad{ }^{2}$ Departamento de Ecologia, Universidade Federal de Goiás, Goiânia, Brazil.

$7 \quad{ }^{3}$ Wildlife Consultor, Madrid, Spain.

8 Corresponding author: Luis M. Carrascal. C/José Gutiérrez Abascal 2, 28006 Madrid, Spain.

9 Email: lmcarrascal@mncn.csic.es

10 Short title: Temperature effects on bird distribution 


\section{Abstract}

Background. Availability of environmental energy, as measured by temperature, is expected to limit the abundance and distribution of endotherms wintering at temperate latitudes. A prediction of this hypothesis is that birds should attain their highest abundances in warmer areas. However, there may be a spatial mismatch between species preferred habitats and species preferred temperatures, so some species might end-up wintering in sub-optimal thermal environments.

Methods. We model the influence of minimum winter temperature on the relative abundance of 106 terrestrial bird species wintering in peninsular Spain, at $10 \times 10 \mathrm{~km}^{2}$ resolution, using 95\%quantile regressions. We analyze general trends across species on the shape of the response curves, the environmental preferred temperature (at which the species abundance is maximized), the mean temperature in the area of distribution and the thermal breadth (area under the abundance-temperature curve).

Results. Temperature explains a low proportion of variation in abundance. The most significant effect is on limiting the maximum potential abundance of species. Considering this upper-limit response, there is a large interspecific variability on the thermal preferences and specialization of species. Overall, there is a preponderance of positive relationships between species abundance and temperature; on average, species attain their maximum abundances in areas $1.9^{\circ} \mathrm{C}$ warmer than the average temperature available in peninsular Spain. The mean temperature in the area of distribution is lower than the thermal preferences of the species.

Discussion. Many species prefer the warmest areas to overwinter, which suggests that temperature imposes important restrictions to birds wintering in the Iberian Peninsula. However, one third of species overwinter in locations colder than their thermal preferences, probably reflecting the interaction between habitat and thermal requirements. There is a high inter-specific variation in the versatility of species using the available thermal space, and the limited effect of temperature highlights the role of other environmental factors determining species abundance. 


\section{INTRODUCTION}

The distribution of overwintering animals is assumed to be strongly influenced by environmental energy availability, notably in regions with a marked year-round seasonality such as temperate ecosystems. Peninsular Spain is an important destination for many avian populations of the southwestern Palearctic during the winter (Moreau, 1972), when there are massive migrations of northern populations towards circum-Mediterranean countries. Even though conditions are milder than in the north, it is an energy-limiting period in which food resources are scarce and/or difficult to locate and the low temperatures impose a high metabolic cost to maintain a constant body temperature for homeothermic animals (Calder \& King, 1974). Specifically, average winter temperature in peninsular Spain $\left(7.2^{\circ} \mathrm{C}\right)$ is well below the lower critical temperature for a broad variety of bird species (ca. $18-22^{\circ} \mathrm{C}$, Calder \& King, 1974; Kendeigh et al., 1977). Thus, winter survival depends primarily on a positive energy balance, obtaining enough food for self-maintenance and reducing metabolic costs of thermoregulation (e.g. Newton, 1998). In this ecological scenario, species abundances are expected to reach their maxima in warmer areas, through the direct effects of reduced thermoregulation costs and reduced mortality by hypothermia, or indirectly via the improvement of the winter foraging environment (e.g., Gosler, 1996; Doherty \& Grubb, 2002; Rogers \& Reed, 2003; Robinson et al., 2007; Cresswell et al., 2009; Carrascal et al., 2012a). However, the availability of "optimal environments", combining preferred temperatures together with other habitat or trophic requirements, may be restricted. As a consequence, the environments in which the individuals of a species end up wintering may show a mean temperature different from the thermal preference of the species (at which the maximum abundances are attained). On the other hand, although general patterns are expected in relation to thermal optima, there might be notable interspecific differences on the thermal tolerance of species. Thermal breadth of species may define how 
62 individuals utilize the thermal space and ultimately the geographical area occupied by species 63 (Slatyer et al. 2013).

64

65

66

67

Moreover, while the abundance of species may be limited by temperature at some points, it might be further limited by other environmental factors related to species-specific habitat or trophic preferences at other locations (Herrando et al. 2011, SEO/BirdLife 2012, Howard et al. 2015). Thus, the correlation between species abundance and temperature may often display a solid distribution as that shown in Figure 1a. The upper limit of this distribution is defined by locations in which temperature is the factor actually limiting abundance, while the points below this limit correspond to locations in which other environmental factors are limiting abundance further than temperature. The upper limit of these distributions would represent the maximum potential abundance of species attainable at each environmental temperature, which in theory is independent of other environmental factors (Cade \& Noon 2003, Fig 1a).

The first goal of this study is to test the hypothesis that minimum winter temperature - as a surrogate of environmental energy availability - limits the maximum potential abundance of terrestrial birds wintering in the Iberian Peninsula, so that warmer environments will have the potential to maintain a higher number of individuals. Specifically, we test two predictions of this hypothesis: (1) that the maximum abundance of species will correlate positively with minimum winter temperature, (2) that, on average, species will prefer temperatures above the mean environmental temperature available in the region. The second goal is to test the hypothesis that as a consequence of species being limited by other factors (e.g., habitat preferences, food availability), mean temperatures at which species are found ( $\left.\mathbf{T}_{\text {MEAN }}\right)$ do not coincide with the preferred temperature at which the species abundance is maximized ( $\left.\mathbf{T}_{\mathbf{P R E F}}\right)$. Finally, we analyze 
84 the interspecific variation on the level of specialization to use the available thermal space (i.e.,

85 the thermal breadth of species, $\mathbf{T}_{\text {BREADTH; }}$ Figure 1b).

86

87

88

89

90

91

92

93

94

95

96

97

98

We modeled the influence of minimum winter temperature on the abundance of 103 species of terrestrial birds wintering in the Iberian Peninsula using quadratic 95\%-quantile regression models (Figure 1a). To analyze macroecological patterns in the abundancetemperature relationship across species, we use the standardized regression coefficients and two parameters derived from quantile regression models: the 'environmental preferred temperature' of species, calculated as the temperature at which its abundance is maximal within the thermal span of the study region, and the 'thermal breadth' of species, calculated as the area under the response curve relative to the maximum abundance of the species (Figure 1b). These measures are able to detect higher inter-specific variability in both thermal preferences and thermal breadth of species than other classical approaches (Villén-Pérez and Carrascal, 2015).

\section{MATERIALS AND METHODS}

\section{Bird abundance and temperature data}

We obtained field data from the national-scale project conducted by SEO/BirdLife for the first Spanish Atlas of Wintering Birds (SEO/BirdLife, 2012). See Figure 2b for the geographical location of the study area within the Western Palearctic. We calculated the 'relative abundance' of each species at 1,689 UTM 10x10 $\mathrm{km}^{2}$ cells, with very good sampling cover, as the frequency of occurrence in sixty 15-min transects sampled throughout three consecutive winters (see a summary of the methods in the Spanish Atlas of Wintering Birds in Text S1). We selected 103 bird species for the analyses, excluding nocturnal and aquatic birds, species that were detected in 
106 less than 50 UTM 10x10 $\mathrm{km}^{2}$ cells, and those that were rare or very difficult to detect (i.e., those

107 with a maximum recorded frequency of occurrence lower than 0.05 , or three 15 -min transects per 10860 transects censused).

109 The Meteorological Spanish agency (www.aemet.es) provided updated GIS temperature 110 data covering the whole Iberian Peninsula, from which we calculated the average minimum 111 winter temperature of each UTM cell as the daily averages during the period of study (mid112 November to mid-February 2007-2010). Average minimum winter temperature during the study 113 period in the 1689 UTM cells considered was highly correlated with average winter temperature $114(\mathrm{r}=0.978)$ and average maximum winter temperature $(\mathrm{r}=0.909)$. The average minimum winter 115 temperature was selected as a measurement of the thermal state of the environment more 116 probably constraining bird distribution and abundance, considering its functional meaning 117 related to maximum thermoregulatory costs. Moreover, minimum temperatures usually occur at 118 night, which is the most constraining period for diurnal species during winter, considering the 119 long duration of nights, foraging inactivity and the lack of heat production from locomotion 120 (Carrascal et al. 2012b).

\section{Data analyses}

122 We analyzed the influence of minimum winter temperature $(\mathrm{T})$ on the relative abundance 123 (A) of each species using quantile regression models at percentiles $50^{\text {th }}, 75^{\text {th }}, 90^{\text {th }}$ and $95^{\text {th }}$ (i.e., $\tau$ $124=0.50,0.75,0.90,0.95 ;$ see Cade \& Noon, 2003 and references therein, Figure 1a). To account 125 for non-linear effects of temperature, we defined the linear and quadratic terms of the 126 relationship $\left(\mathrm{A}=\mathrm{a}+\mathrm{bT}+\mathrm{cT}^{2}\right)$. We standardized the original temperature variable $\mathrm{T}$, and its

127 squared term $\mathrm{T}^{2}$, to mean $=0$ and $\mathrm{sd}=1$ prior to data analyses, in order to obtain standardized 128 regression coefficients, also called beta regression coefficients. Under this standardization, the 
129 magnitude of beta coefficients allows to compare the relative contribution of each independent

130 variable in the prediction of the response variable because predictors are on the same

131 measurement scale. We estimated pseudo- $\mathrm{R}^{2}$ for each quantile regression model as a goodness-

132 of-fit measure (Konker and Machado 1999), analogous but not exactly homologous to $\mathrm{R}^{2}$ in least

133 square models (i.e., how well the quantile regression represents the variability observed in the

134 response variable; a higher pseudo- $\mathrm{R}^{2}$ indicates a better fit). In addition, we calculated the

135 increase in AIC of these models with respect to the null model as a measure of the likelihood of

136 the model (Burham \& Anderson 2002).

137 We obtained the environmental preferred temperature $\left(\mathbf{T}_{\mathbf{P R E F}}\right)$ by solving the equation $d \mathrm{~A}$

$138 \cdot d \mathrm{~T}^{-1}=0$ in quadratic $95 \%$-quantile regression models. Then, we calculated the mean

139 temperature in the area of distribution $\left(\mathbf{T}_{\text {MEAN }}\right)$ as the weighted average of the winter minimum

140 temperature of the UTM cells where the species were present, using the relative occurrence of

141 species in the sixty 15-min transects. Finally, we obtained the thermal breadth of species

142 ( $\mathbf{T}_{\text {BREADTH }}$ ) by integrating $\mathrm{A} \cdot d \mathrm{~T}$ in quadratic $95 \%$-quantile regression models between -2 and

$14310^{\circ} \mathrm{C}$, standardizing the maximal abundances of all species to 1 (Figure $1 \mathrm{~b}$ ); this index ranges

144 from 0 to 1.

145 We carried out all data analyses with R 1.8-10 (R Development Core Team 2014), using 146 packages quantreg version 5.21 (Koenker 2015) and Hmisc version 3.17-3 (Harrell 2015). See

147 Figure 2 for three example species, showing different patterns of relationship between relative

148 abundance and average winter minimum temperature. The script we employed in analyses is

149 found in Code and Data S2.

150

\section{RESULTS}


153 wedge-shaped point cloud in all species, with values varying from zero to an upper limit of

154 abundance (Figures 1 and 2). Minimum winter temperature explains an average of 2.7\%

$155(\mathrm{se}=0.534), 4.8 \%(0.773), 7.1 \%(0.924)$ and $8.7 \%(0.964)$ of species abundances using quantile

156 regression models at percentiles $50 \%, 75 \%, 90 \%$ and $95 \%$, respectively (see pseudo- $\mathrm{R}^{2}$ for

157 quantile regression models of all species in Table S3). Only in ten out of 103 species, 95\%-

158 quantile regression models attain figures of pseudo- $\mathrm{R}^{2}$ higher than $25 \%$, while it is lower than

$1595 \%$ in 50 species. There is a significant increase in pseudo- $\mathrm{R}^{2}$ from the percentile $50 \%$ to $95 \%$

160 (repeated measure ANOVA testing for the linear contrast of increase from $50 \%$ to $95 \%$ :

$\left.161 \quad \mathrm{~F}_{1,102}=64.49, \mathrm{p}<<0.001\right)$.

162 In 93 out of 103 species, the 95\%-quantile regression models including the linear and 163 quadratic terms of temperature attain AIC figures that are 13.82 units lower than those AIC

164 figures obtained for 95\%-quantile null regression models (i.e., the temperature models are 1,000 165 times better in explaining the variation in relative abundance of the species than the null models; $1661,000=\exp [-0.5 * 13.816] ;$ Burham \& Anderson 2002). In other ten species the $\Delta \mathrm{AIC}$ is higher 167 than -6 (see Table S3). Standardized lineal regression coefficients b in the 93 species with "significant" 95\%quantile regression models are on average positive, and significantly different from zero ( $\mathrm{t}$ test $=$ 4.994, df $=92, p<<0.001 ;$ Table 1, Table S3). Standardized quadratic regression coefficients c

171 show predominantly negative values, on average significantly different from zero (across-species 172 comparison: $\mathrm{t}$ test $=-3.144, \mathrm{df}=92, \mathrm{p}=0.002$ ), defining a hump-shaped relationship between

173 temperature and the relative abundance of bird species. Linear terms $\mathbf{b}$ have larger absolute

174 values than the quadratic terms $\mathbf{c}$ (average of absolute figures of $\mathbf{b}$ and $\mathbf{c}: 4.97$ and 3.05, 
175 respectively; paired $t$ test: $\mathrm{t}=5.51, \mathrm{df}=92, \mathrm{p}<<0.001)$. Therefore, the linear increase of relative

176 abundance with winter temperature is, on average, positive and more important than the

177 curvilinear pattern defining maxima.

178 The average $\mathbf{T}_{\mathbf{P R E F}}$ is $4.36^{\circ} \mathrm{C}$ for 93 species with "significant" $95 \%$-quantile regression 179 models (range: $-2{ }^{\circ} \mathrm{C}$ to $10^{\circ} \mathrm{C}$; Table 1 , Table $\mathrm{S} 3$ ), and this average is significantly higher than 180 the average minimum environmental temperature available during winter in peninsular Spain $181\left(2.55^{\circ} \mathrm{C}\right.$; t-test: $\left.\mathrm{t}=3.70, \mathrm{df}=92, \mathrm{p}<0.001\right) . \mathbf{T}_{\text {PREF }}$ is lower than $0{ }^{\circ} \mathrm{C}$ in 24 out of 93 species 182 (i.e., preferences for colder areas; e.g., Dryocopus martius, Cinclus cinclus, Turdus pilaris, 183 Serinus citrinella, Fringilla montifringilla, Emberiza cia), while it is higher than $5{ }^{\circ} \mathrm{C}$ in 40 species (i.e., preferences for warmer areas; e.g., Elaneus caeruleus, Upupa epops, Alcedo atthis, Burhinus oedicnemus, Ptynoprogne rupestris, Phylloscopus collybita, Troglodytes troglodytes, Cisticola juncidis, Sylvia undata, see Table S3). species (range: $-0.20{ }^{\circ} \mathrm{C}$ to $5.51{ }^{\circ} \mathrm{C}$; Table 1 , Table $\mathrm{S} 3$ ). In 77 out of 103 species $\mathbf{T}_{\text {MEAN }}$ is significantly different from the average minimum temperature available in winter in peninsular Spain $\left(2.55^{\circ} \mathrm{C}\right.$; significant t-tests after the sequential Bonferroni correction), with 35 bird species whose distribution correspond to colder conditions than average, and 42 species inhabiting warmer areas than average. Other 26 species do not show any clear, significant, preference for warmer or colder areas in peninsular Spain.

$\mathbf{T}_{\text {PREF }}$ and $\mathbf{T}_{\text {MEAN }}$ are highly correlated $(\mathrm{r}=0.856, \mathrm{n}=93, \mathrm{p}<<0.001 ;$ Figure 3$)$, although

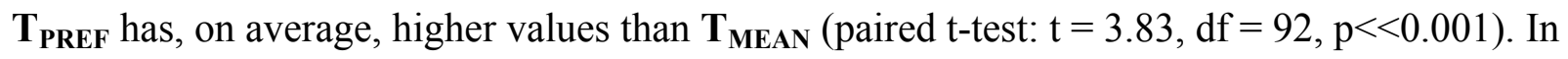
fact, there are 32 species with $\mathbf{T}_{\text {PREF }}>8{ }^{\circ} \mathrm{C}$ that show a $\mathbf{T}_{\text {MEAN }} 4.5$ to $8.3^{\circ} \mathrm{C}$ colder. Conversely, 197 there are 21 species with $\mathbf{T}_{\text {PREF }}=-2{ }^{\circ} \mathrm{C}$ and a $\mathbf{T}_{\text {MEAN }} 1.8$ to $4.1{ }^{\circ} \mathrm{C}$ higher. 
$\mathbf{T}_{\text {BREADTH }}$ is on average 0.64 for all studied species (range: 0.26 to $1.00, \mathrm{n}=103$ species;

199

200

201

202

203

204

205

206

207

208

209

210

211

212

213

214

215

216

217

218

219

220 see Table 1, Table S3). It is low (i.e., thermal specialists, $<0.33$ ) in species such as Dryocopus martius, Oenanthe leucura, Turdus pilaris, Remiz pendulinus, Serinus citrinella) and high (i.e., thermal generalists, >0.90) in species such as Accipiter nisus, Turdus merula, Parus major, Corvus monedula, Carduelis cannabina, Fringilla coelebs (see Appendix 2). In those ten species in which 95\%-quantile regression models are "non-significant" the average thermal breadth is 0.93, both facts indicating the independence of the distribution of these species with respect to temperature.

\section{DISCUSSION}

The maximum abundance of birds wintering in the Iberian Peninsula is influenced by average winter minimum temperature in $90 \%$ of the studied species. As a general trend, the relative abundance of species increases with temperature and, on average, species reach their maximum abundances at temperatures $1.9^{\circ} \mathrm{C}$ warmer than the average winter minimum temperature available in the study region. Nevertheless, temperature alone can only explain a small proportion of variation in maximum abundance, and the shapes of point clouds suggest that other environmental factors that were not included in temperature models, such as food availability or habitat structure, may be more relevant to explain species abundance. The relative importance of temperature depends on the species: the thermal breadth of the studied species varies from 0.26 to 1.00 , reflecting a broad spectrum from thermal specialists to thermal generalists (Table S3; Moussus et al., 2011; Barnagaud et al. 2012).

In a winter scenario with temperatures well below the thermoneutral zone, warmer environments may significantly reduce bird metabolic costs and improve the foraging 
221 environment, overall reducing winter mortality rates (Calder \& King, 1974; Kendeigh et al.,

222 1977; Root 1988; Canterbury 2002; Meehan et al. 2004; Cresswell et al. 2009; Zuckerber et al.

223 2011). Nevertheless our results show that the relationships between bird abundance and

224 temperature are variable and idiosyncratic (see also Reif et al. 2010; La Sorte \& Jetz 2012;

225 Fraixedas et al. 2015). For instance, 33\% of species show statistical significant preferences for

226 environments colder than average conditions (see $\mathbf{T}_{\mathbf{P R E F}}$ in Table S3). Contrary to the general

227 positive relationships between winter temperature and bird abundance, which are easy to explain

228 according to thermoregulatory costs and food accessibility, these negative relationships are

229 hardly explainable using metabolic arguments for endotherms in wintertime. There might exist

230 other important aspects of bird natural history, such as specialized food preferences or selection

231 for particular habitats with a restricted spatial distribution that are responsible for the emergence

232 of those negative relationships between temperature and animal abundance. This may be the case

233 of resident species with restricted habitat preferences, such as for example very mature and

234 extensive forests (e.g., Dryocopus martius), mountain streams (Cinclus cinclus), or alpine rock

235 outcrops (Prunella collaris; Herrando et al. 2011), and species with a very specialized diet such

236 as the fruits of the Spanish juniper tree (Juniperus thurifera) that grows in highlands of

237 continental cold climate (Turdus torquatus, T. pilaris, T, viscivorus; Tellería et al., 2014), or

238 seeds provided by pine species with small cones in montane coniferous forests (Serinus

239 citrinella; Borras et al. 2010). If these habitats and food types are unequivocally linked with

240 areas of cold climate, then the negative relationship of those species with temperature may be the

241 casual consequence of functional responses to habitats and food resources (Barnagaud et al.

242 2012). 
Our results suggest that temperature has little importance in limiting winter bird

244 distribution (average pseudo- $\mathrm{R}^{2}$ of $8.7 \%$ for the $95 \%$-quantile regression models, and only ten

245 species with pseudo- $\left.\mathrm{R}^{2}>25 \%\right)$. The steady increase of pseudo- $\mathrm{R}^{2}$ from the median $(50 \%$

246 quantile) to the maximum response (95\% quantile) shows that the influence of temperature on

247 bird distribution is more clearly revealed at the upper edge of the wedge-shaped pattern of

248 covariation abundance - temperature, where the limiting effect of temperature surpasses that of

249 other factors affecting bird abundance (see Figure 1a). The detected meager influence of

250 temperature on the spatial variation of winter bird abundance is consistent with results obtained

251 in other European areas (Reif et al. 2010; Dalby et al. 2013; Fraixedas et al. 2015), suggesting

252 that other factors such as food and habitat availability are more important governing winter bird

253 distribution in this region of the southwestern Palearctic (see also Carrascal et al. 2012a, 2012b

254 for the competing effects of food, vegetation and temperature on the winter abundance of small

255 passerines at smaller spatial scales in the Iberian Peninsula).

Quantile regression is a method of analyzing the unequal variation in a variable of interest

257

258

259

260

261

262

263

264

265 along a set of predictor of variables when there are multiple rates of change (or slopes) from the minimum to the maximum response (Cade et al. 1999; Cade and Noon 2003). This approach allows the identification of limiting factors, paying more attention to the slopes near the maximum response (e.g., maximum abundance attained at each temperature), which provides a thorough picture of the patterns of covariation between the animal abundance and temperature.

Thus, the estimation of the response of a high quantile of population density to a measured predictor variable is generally considered to be a better estimate of the effect of that variable as a limiting factor than the estimate of the response to the mean calculated with least squares. This is because other unmeasured variables may be the active limiting constraint in the dependent 
266 variable of interest, through their correlations with the measured predictor (Borsuk 2008). For

267 example, if a UTM cell has a winter temperature that approaches the thermal preference of a

268 species but lacks the habitat with the vegetation structure characteristics and food availability

269 that configure the spatial-trophic niche of the species, the species should be probably very scarce

270 in that UTM cell (e.g., Sylvia melanocephala may be scarce in a warm cell with minimum winter

271 temperature $9{ }^{\circ} \mathrm{C}$ but lacking Mediterranean maquis with high abundance of ripe fruits). That

272 sample unit will occupy a low position in the wedge-shaped pattern depicted by Figure la.

273 Therefore, estimating the upper edge of the wedge-shaped pattern of covariation abundance -

274 temperature allows for the identification of the limiting effect of temperature on bird abundance,

275 disregarding the probable interactions between temperature and other limiting predictors

276 (measured or unmeasured). This is a sound concern, as the influence of temperature on bird

277 distribution and abundance is probably mediated through surrogate effects of spatial variables,

278 habitat preferences or resource availability (see Aragón et al. 2010 for direct and indirect effects

279 of climatic and non-climatic factors on distribution of ectothermic and endothermic vertebrates

280 in the Iberian Peninsula). For example, Repasky (1991) found little evidence to support that the

281 northern distributions of North American wintering birds are governed principally by

282 temperature, suggesting that temperature probably plays a role through interactions with biotic

283 factors such as food, habitat structure and competition. The importance of these interactions on

284 bird abundance distribution, is clearly reflected by the differences between the mean winter

285 minimum temperature in those UTM cells where the species were present $\left(\mathbf{T}_{\text {MEAN }}\right)$ and the

286 preferred temperature (T $\mathbf{T}_{\text {PREF }}$ ) derived from quadratic 95\%-quantile regression models (Figure

287 3). Although both parameters are highly correlated, most individuals end-up overwintering in

288 locations that are colder than the species thermal preferences, which may reflect a limitation of 
289 sites combining thermal and other environmental optima. For instance, insectivorous small

290 passerines, such as Cettia cetti, Sylvia undata, Motacilla alba or Saxicola rubicola, occupy areas

291 of peninsular Spain that are ca. $6^{\circ} \mathrm{C}$ colder than their preferred temperatures (see Table S3),

292 probably because they lack their preferred habitats in those warm areas. Considering this

293 evidence, the low use of quantile regressions in the study of animal distribution patterns in

294 relation to climate is highly surprising, a fact that may be a constraint in ecologists' ability to

295 analyze the influence of climatic variables for elucidating the underlying patterns (Austin 2007,

296 Vaz et al. 2008).

The general preference for warmer environments that we found suggest that winters will

be less restrictive for most birds wintering in the Iberian peninsula under future climate warming scenarios (IPCC, 2007; Brunet et al., 2009; Stocker et al. 2013), though the impact of changes will depend on species-specific thermal preferences and plasticity (Khaliq et al. 2014, PearceHiggins et al. 2015, Gaüzère et al. 2015). Zuckerberg et al. (2011) showed for birds wintering in

North America that average minimum temperature is an important factor limiting bird distributions, and that local within-winter extinction probabilities are lower, and colonization probabilities higher, at warmer sites, supporting the role of climate-mediated range shifts. that prefer higher winter temperatures and that mainly rely on arthropods and fruits as winter food (e.g., Upupa epops, Ptynoprogne rupestris, Troglodytes troglodytes, Luscinia svecica, vein, Tellería et al. (2016) found that according to temperature increase projections for 20502070, two insectivorous passerines wintering in the Western Mediterranean basin (Anthus pratensis and Phylloscopus collybita) will broaden their distribution ranges into the cold 
312 highland expanses typical of the western Mediterranean. 'Space-for-time' substitution when

313 forecasting temporal trends from spatial climatic gradients must be taken with care (La Sorte et

314 al. 2009), as well as the potential interaction of climate and habitat changes on species responses

315 (Chamberlain et al. 2013). Nevertheless, these forecasts on bird distributions are supported by

316 the analyses of recent avian populations and winter minimum temperature changes in North

317 America, where shifting winter climate has provided an opportunity for smaller, southerly

318 distributed species to colonize new regions (Prince and Zuckerberg 2015).

\section{CONCLUSIONS}

320 This study highlights the high interspecific variability on the response to temperature and

321 thermal tolerance. Bird species wintering in peninsular Spain range from the coldest to the

322 warmest thermal preferences and from thermal specialists to generalists. Nevertheless, the

323 general trend is to select the warmest areas, so that abundance of most species increases with

324 temperature and is predicted to reach its maximum at temperatures higher than the average

325 available temperature in the study region. Even though species attain their maximum abundances

326 at warm areas, a large proportion of the area of distribution of the studied species is in colder

327 locations, probably reflecting a limitation of sites combining thermal optima with other

328 environmental preferences of a species. Our results suggest that minimum winter temperature

329 functions as a physiological constraint on the maximum potential abundance attainable by a

330 species at a certain location, though other environmental factors may be more relevant than

331 temperature defining the biogeographical patterns of species.

\section{Aknowledgements}


333 Juan Carlos del Moral (SEO / BirdLife) provided the raw data from the Winter Spanish Bird

334 Atlas. We also thank Jorge M. Lobo for helpful comments on a first draft of the paper and C.

335 Jasinski for improving the English of the manuscript.

336

337

338

339

340

341

342

343

344

345

346

347

348

349

350

351

352

353

354

355

356

357

358

359

\section{REFERENCES}

Aragón, P., Lobo, J.M., Olalla-Tárraga, M.A. \& Rodríguez, M.A. (2010) The contribution of contemporary climate to ectothermic and endothermic vertebrate distributions in a glacial refuge. Global Ecology and Biogeography, 19, 40-49.

Austin, M. (2007) Species distribution models and ecological theory: A critical assessment and some possible new approaches. Ecological Modelling, 200, 1-19.

Barnagaud, J. Y., Devictor, V., Jiguet, F., Barbet-Massin, M., Le Viol, I., \& Archaux, F. (2012). Relating habitat and climatic niches in birds. PLoS One, 7(3), e32819.

Borras, A., Senar, J.C., Alba-Sánchez, F., López-Sáez, J.A., Cabrera, J., Colomé, X. \& Cabrera, T. (2010) Citril finches during the winter: patterns of distribution, the role of pines and implications for the conservation of the species. Animal Biodiversity and Conservation, $33,89-115$.

Borsuk, M.E. (2008) Statistical Prediction. Pp. 3362-3373 in S.E. Jorgensen and B.D. Fath (eds). Encyclopedia of Ecology. Elsevier B.V., Amsterdam, The Netherlands.

Brunet, M., Casado, M.J., de Castro, M., Galán, P., López, J.A., Martín, J.M., Pastor, A., Petisco, E., Ramos, P., Ribalaygua, J., Rodríguez, E., Sanz, I., \& Torres, L. (2009) Generación de escenarios regionalizados de cambio climático para España. Ministerio de Medio Ambiente y Medio Rural y Marino, Agencia Estatal de Meteorología, Madrid.

Burnham, K.P. \& Anderson, D.R. (2002) Model selection and multi-model inference: a practical information-theoretic approach. Springer.

Cade, B.S., Terrell, J.W. \& Schroeder, R.L. (1999) Estimating effects of limiting factors with regression quantiles. Ecology, 80, 311-323.

Cade, B.S. \& Noon, B.R. (2003) A gentle introduction to quantile regression for ecologists. Frontiers in Ecology and the Environment, 1, 412-420. 
360

361

362

363

364

365

366

367

368

369

370

371

372

373

374

375

376

377

378

379

380

381

382

383

384

385

386

387

388

Calder, W. \& King, J. (1974) Thermal and caloric relations of birds. Avian biology, volume 4 (ed. by D. Farner and J. King), pp. 259-413. Academic Press, New York.

Canterbury, G. (2002) Metabolic adaptation and climatic constraints on winter bird distribution. Ecology 83, 946-957.

Carrascal, L.M., Villén-Pérez, S., Seoane, J. (2012a) Thermal, food and vegetation effects on winter bird species richness of Mediterranean oakwoods. Ecological Research, 27, 293302.

Carrascal, L.M., Seoane, J. \& Villén-Pérez, S. (2012b) Temperature and food constraints in wintering birds - an experimental approach in montane Mediterranean oakwoods. Community Ecology, 13, 221-229.

Chamberlain, D. E., Negro, M., Caprio, E., \& Rolando, A. (2013). Assessing the sensitivity of alpine birds to potential future changes in habitat and climate to inform management strategies. Biological conservation, 167, 127-135.

Cresswell, W., Clark, J.A. \& Macleod, R. (2009) How climate change might influence the starvation-predation risk trade-off response. Proceedings of the Royal Society B: Biological Sciences, 276, 3553-3560.

Dalby, L., Fox, A.D., Petersen, I.K., Delany, S., Svenning, J.C. (2013) Temperature does not dictate the wintering distributions of European dabbling duck species. Ibis, 155, 80-88.

Doherty, P.F. \& Grubb, T.C. (2002) Survivorship of permanent-resident birds in a fragmented forested landscape. Ecology, 83, 844-857.

Fraixedas, S., Lehikoinen, A. \& Linden, A. (2015) Impacts of climate and land-use change on wintering bird populations in Finland Journal of Avian Biology, 46, 63-72

Gaüzère, P., Jiguet, F., \& Devictor, V. (2015). Rapid adjustment of bird community compositions to local climatic variations and its functional consequences. Global change biology, 21(9), 3367-3378.

Gosler, A.G. (1996) Environmental and social determinants of winter fat storage in the great tit Parus major. Journal of Animal Ecology 65, 1-17.

Harrell, F.E. (2015) Package 'Hmisc'. https://cran.r-project.org/web/packages/Hmisc/ Hmisc.pdf. 
389 390

391

392

393

394

395

396

397

398

399

400

401

402

403

404

405

406

407

408

409

410

411

412

413

414

415

416

Herrando, S., Brotons, L., Estrada, J., Guallar, S. \& Anton, M. (2011) Catalan Winter Bird Atlas 2006-2009. Institut Catalá d'Ornitologia y Lynx Edicions, Barcelona.

Howard, C., Stephens, P. A., Pearce-Higgins, J. W., Gregory, R. D., \& Willis, S. G. (2015). The drivers of avian abundance: patterns in the relative importance of climate and land use. Global Ecology and Biogeography, 24(11), 1249-1260.

IPCC (2007) IPCC Fourth Assessment Report: Climate Change 2007. Cambridge University Press, Cambridge and New York.

Kendeigh, S., Dol'nik, V. \& Gavrilov, V. (1977) Avian energetics. Granivorous birds in ecosystems (ed. by J. Pinowski and S. Kendeleigh), pp. 127-204. Cambridge University Press, New York.

Khaliq, I., Hof, C., Prinzinger, R., Böhning-Gaese, K., \& Pfenninger, M. (2014). Global variation in thermal tolerances and vulnerability of endotherms to climate change. Proceedings of the Royal Society of London B: Biological Sciences, 281(1789), 20141097.

Konker, R. (2015) Package 'quantreg'. https://cran.r-project.org/web/packages/ quantreg/quantreg.pdf.

Koenker, R. \& Machado, J. (1999) Goodness of Fit and Related Inference Processes for Quantile Regression. Journal of the American Statistical Association, 94, 448, 1296-1310.

La Sorte, F.A., Lee, T.M., Wilman, H., Jetz, W. (2009). Disparities between observed and predicted impacts of climate change on winter bird assemblages. Proc. R. Soc. London B, $276,3167-3174$.

La Sorte, F.A. \& Jetz, W. (2012) Tracking of climatic niche boundaries under recent climate change. Journal of Animal Ecology, 81 , 914-925.

Meehan, T.D., Jetz, W. and Brown, J.H. (2004). Energetic determinants of abundance in winter landbird communities. Ecology Letters, 7, 532-537.

Moreau, R.E. (1972): The Palaearctic-African bird migration systems. Academic Press, London.

Moussus, J.-P., Clavel, J., Jiguet, F. \& Julliard, R. (2011) Which are the phenologically flexible species? A case study with common passerine birds. Oikos, 120, 991-998. 
417 Newton, I. (1998) Population limitation in birds. Academic Press, London.

418 Pearce-Higgins, J. W., Eglington, S. M., Martay, B., \& Chamberlain, D. E. (2015). Drivers of 419

420

421

422

423

424

425

426

427

428

429

430

431

432

433

434

435

436

437

438

439

440

441

442

443

climate change impacts on bird communities. Journal of Animal Ecology, 84(4), 943-954.

Prince, K. \& Zuckerberg, B. (2015). Climate change in our backyards: the reshuffling of North America's winter bird communities. Global Change Biology, 21, 572-585.

R Core Team (2015). R: A language and environment for statistical computing. R Foundation for Statistical Computing, Vienna, Austria. URL http://www.R-project.org/.

Reif, J., Telensky, T., Stastny, K., Bejcek, V. \& Klvana, P. (2010) Relationships between winter temperature and breeding bird abundance on community level: importance of interspecific differences in diet. Folia Zoologica, 59, 313-322.

Repasky, R.R. (1991) Temperature and the northern distributions of wintering birds. Ecology, 72, 2274-2285.

Robinson, R.A., Baillie, S.R. \& Crick, H.Q.P. (2007) Weather-dependent survival: implications of climate change for passerine population processes. Ibis, 149, 357-364.

Rogers, C.M. \& Reed, A.K. (2003) Does avian winter fat storage integrate temperature and resource conditions? A long term study. Journal of Avian Biology, 34, 112-118.

Root T, (1988) Energy constraints on avian distributions and abundances. Ecology 69, 330-339.

SEO/BirdLife. (2012) Atlas de las aves en invierno en España 2007-2010. Ministerio de Agricultura, Alimentación y Medio Ambiente - SEO/BirdLife, Madrid.

Slatyer, R.A., Hirst, M. \& Sexton, J.P. (2013) Niche breadth predicts geographical range size: a general ecological pattern. Ecology Letters, 16 (8), 1104-1114.

Stocker, T.F., Qin, D., Plattner, G.K., Tignor, M., Allen, S.K., Boschung, J., Nauels, A., Xia, Y., Bex, V. \& Midgley, P.M. . (2013) Fifth Assessment Report of the Intergovernmental Panel on Climate Change. Cambridge: Cambridge University Press.

Tellería, J.L., Carrascal, L.M. \& Santos, T. (2014) Species abundance and migratory status affects large-scale fruit tracking in thrushes (Turdus spp.) Journal of Ornithology, 155, 157-164. 
444 Tellería, J.L., Fernández-López, J. \& Fandos, G. (2016) Effect of climate change on 445 mediterranean winter ranges of two migratory passerines. PLOS ONE, 11, e0146958.

446 Vaz, S., Martin, C.S., Eastwood, P.D., Ernande, B., Carpentier, A., Meaden, G.J. \& Coppin, F. 447 (2008) Modelling species distributions using regression quantiles. Journal of Applied $448 \quad$ Ecology, 45, 204-217

449 Villén-Pérez, S., Carrascal, L.M. (2015) Occurrence data may provide unreliable thermal 450 preferences and breadth of species. Current Zoology, 61, 972-982.

451 Zuckerberg, B., Bonter, D.N., Hochachka, W.M., Koenig, W.D., De Gaetano, A.T., Dickinson, 452 J.L. (2011). Climatic constraints on wintering bird distributions are modified by 453 urbanization and weather. Journal of Animal Ecology, 80, 403-413. 
455 Table 1. Parameters of the response of species abundance to winter temperature. Figures

456 are mean, standard deviation and range of parameters derived from 95\%-quantile regression

457 models describing the influence of minimum winter temperature on abundance of bird species

458 wintering in peninsular Spain, sampled at 1689 UTM 10x10 km² cells in three consecutive

459 winters (2008-2011). Sample size is 93 species when considering only significant models with a

460 reduction in AIC figures ( $\triangle \mathrm{AIC}$ ) lower than -13.82 units, and 103 species when significance of

461 models is not relevant and therefore all species are considered. Detailed data for all species are

462 shown in Table S3.

\begin{tabular}{lrcrr} 
& mean & sd & range & $\mathrm{n}$ \\
\hline Standardized linear coefficient, $\mathbf{b}$ & 3.22 & 6.22 & $-9.38 / 18.94$ & 93 \\
Standardized curvilinear coefficient, $\mathbf{c}$ & -1.43 & 4.39 & $-18.12 / 7.54$ & 93 \\
Environmental preferred temperature $\left({ }^{\circ} \mathbf{C}\right), \mathbf{T}_{\text {PREF }}$ & 4.36 & 4.72 & $-2 / 10$ & 93 \\
Mean temperature on distribution areas $\left({ }^{\circ} \mathrm{C}\right), \mathbf{T}_{\text {MEAN }}$ & 2.75 & 1.10 & $-0.2 / 5.5$ & 103 \\
Thermal breadth, $\mathbf{T}_{\text {BREADTH }}$ & 0.64 & 0.20 & $0.26 / 1$ & 103
\end{tabular}

b, c: linear and quadratic regression coefficients obtained from $95 \%$-quantile regression models on the effect of minimum winter temperature on the relative abundance of species; $\mathbf{T}_{\mathbf{P R E F}}$ : winter minimum temperature at which the relative abundance of the species is maximized; $\mathbf{T}_{\text {MEAN }}$ : mean of average winter minimum temperature in those UTM cells where the species were present, weighed by the relative abundance of the specie at the cell; $\mathbf{T}_{\text {BREADTH: }}$ area under the curve defined by the second order polynomial equation that relates the relative abundance of species to the temperature using the coefficients of the $95 \%$-quantile regression models. n: number of species considered. 
471 Figure 1. Representation of environmental preferred temperature $\left(\mathbf{T}_{\text {PREF }}\right)$, mean

472 temperature ( $\left.\mathbf{T}_{\text {MEAN }}\right)$ and thermal breadth ( $\left.\mathbf{T}_{\text {BREATH }}\right)$ of an example specie. (a) Abundance of

473 Columba palumbus in relation to minimum winter temperature along 1689 UTM cells, and

474 fitting curves for quantile regression models (from top to bottom: models on $95^{\text {th }}, 75^{\text {th }}, 50^{\text {th }}$ and

$47525^{\text {th }}$ percentiles). Relative abundance is the number of $15 \mathrm{~min}$ transects over 60 in which the

476 species is detected at each UTM 10x10 $\mathrm{km}^{2}$ cell. (b) $\mathbf{T}_{\text {PREF }}, \mathbf{T}_{\text {MEAN }}$ and $\mathbf{T}_{\text {BREATH }}$ of Columba

477 palumbus. Environmental preferred temperature $\left(\mathbf{T}_{\mathbf{P R E F}}\right)$ is the temperature at which the

478 maximum abundance of the species is predicted by the quantile regression model for percentile

$47995^{\text {th }}$ in (a). Mean temperature $\left(\mathbf{T}_{\text {MEAN }}\right)$ is the mean winter minimum temperature in those UTM

480 cells where the species was present, weighed by the relative abundance of the species at each

481 cell. Thermal breadth ( $\mathbf{T}_{\text {BREATH }}$ ) is the standardized area under the curve of quantile regression

482 model for percentile $95^{\text {th }}$ in (a), from -2 to $10^{\circ} \mathrm{C}$ (shaded area in b). 

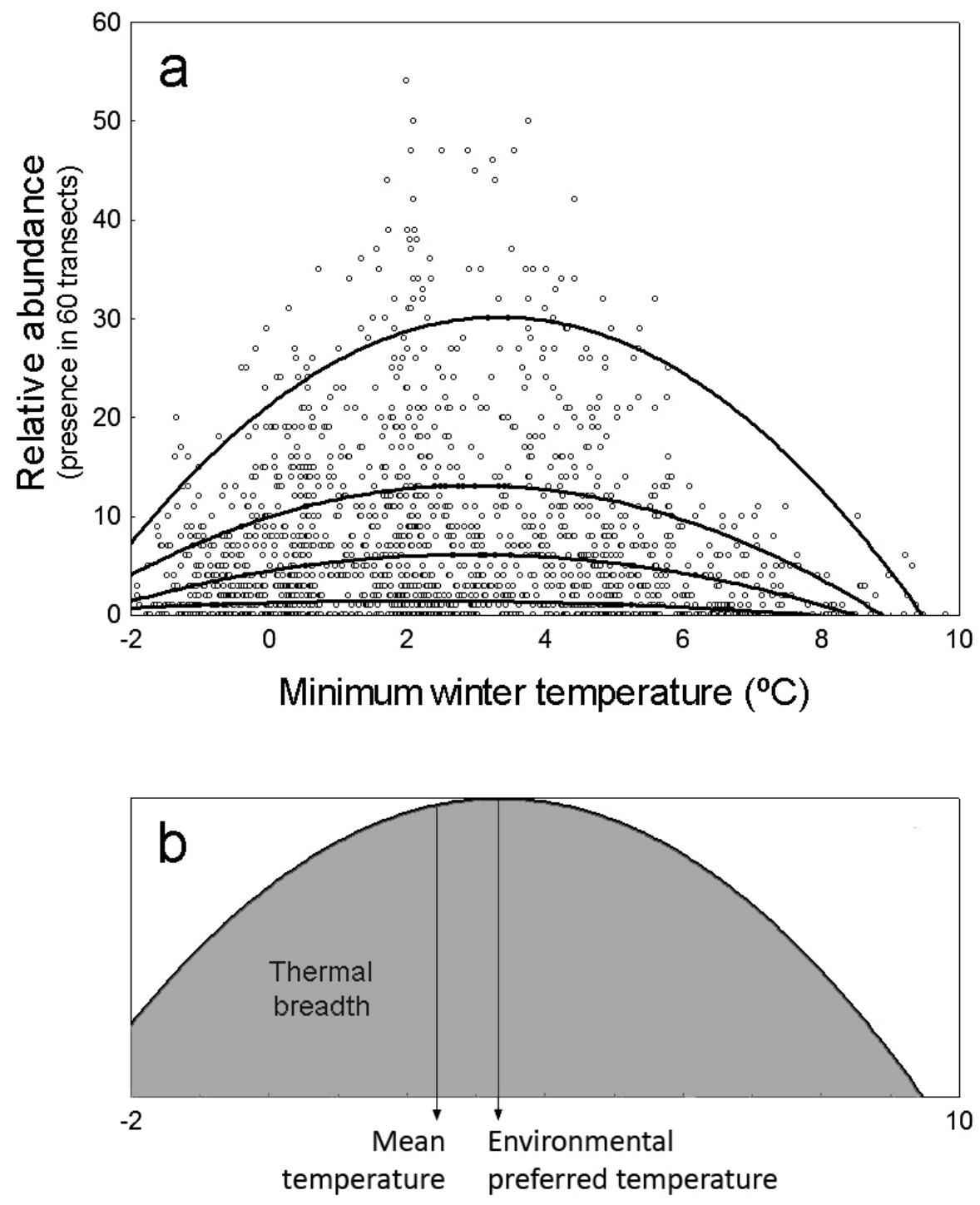
486 Figure 2. Minimum winter temperature $\left({ }^{\circ} \mathrm{C}\right)$ and relative abundance of three example bird 487 species in peninsular Spain, and relationship between these variables. (a) Minimum winter 488 temperatures in the study area (peninsular Spain). (b) Location of the study area (black) within 489 the western Palearctic (dark grey). (c, e, g) Winter relative abundance of three sample species 490 (Saxicola rubicola, Erithacus rubecula and Turdus viscivorus, respectively), at 1689 UTM $49110 \times 10 \mathrm{~km}^{2}$ cells within the study area, sampled in three consecutive winters (2008-2011). 492 Relative abundance is the frequency of occurrence in sixty 15-min linear transects carried out in 493 each UTM cell. (d, f, h) Relationship between the relative abundance of these species and 494 minimum winter temperature, as modeled by quadratic 95\%-quantile regression models. 

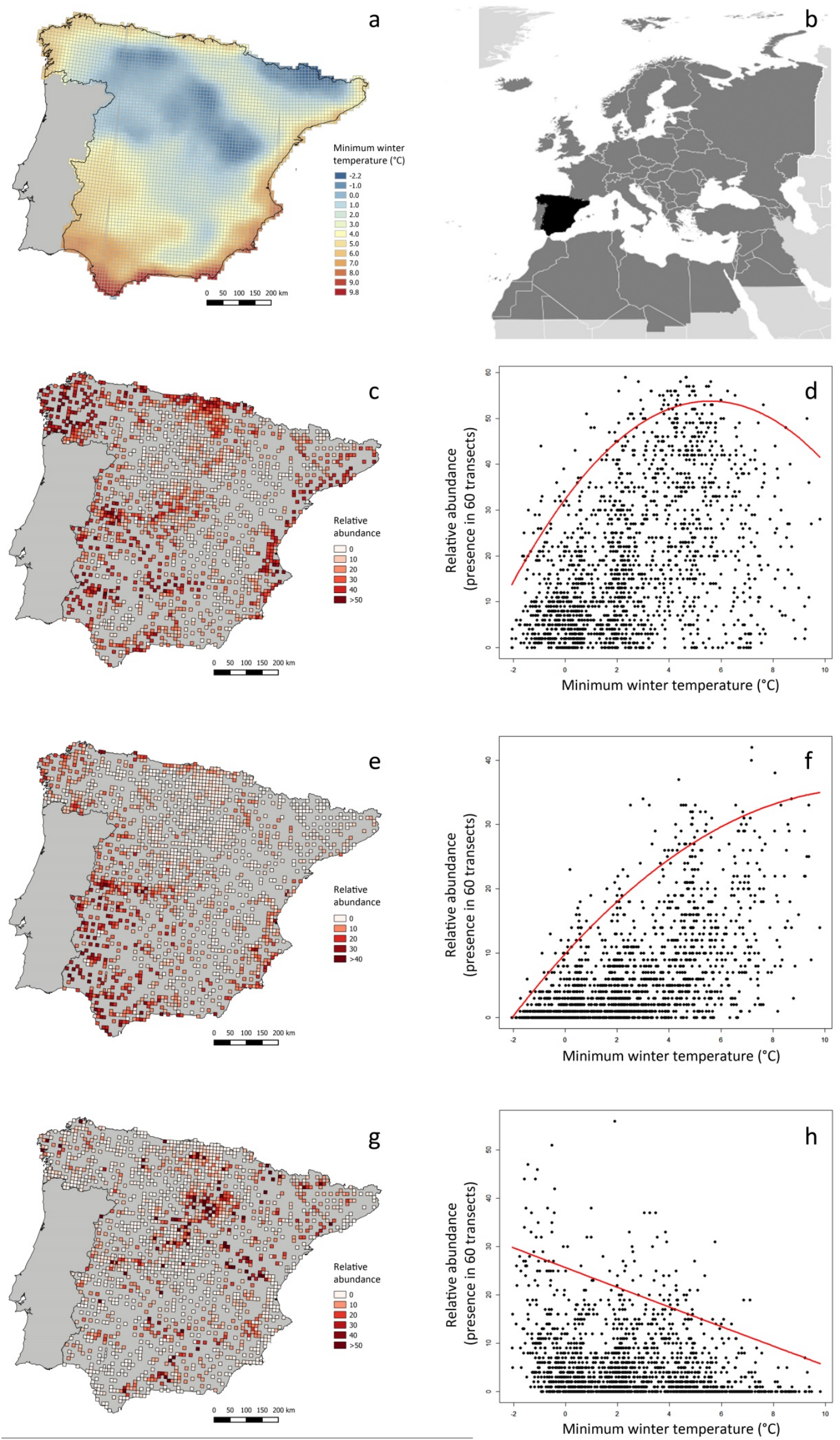
496 Figure 3. Relationship between $\mathbf{T}_{\text {PREF }}$ and $\mathbf{T}_{\text {MEAN }}$ for 93 bird species wintering in peninsular

497 Spain. The graph shows 93 species for which the 95\%-quantile regression models including the

498 linear and quadratic terms of temperature attained AIC figures that were 13.82 units lower than

499 those AIC figures obtained for 95\%-quantile null regression models. Solid line represents the

500 linear regression between $\mathrm{T}_{\mathrm{PREF}}$ and $\mathrm{T}_{\mathrm{MEAN}}$.

501 


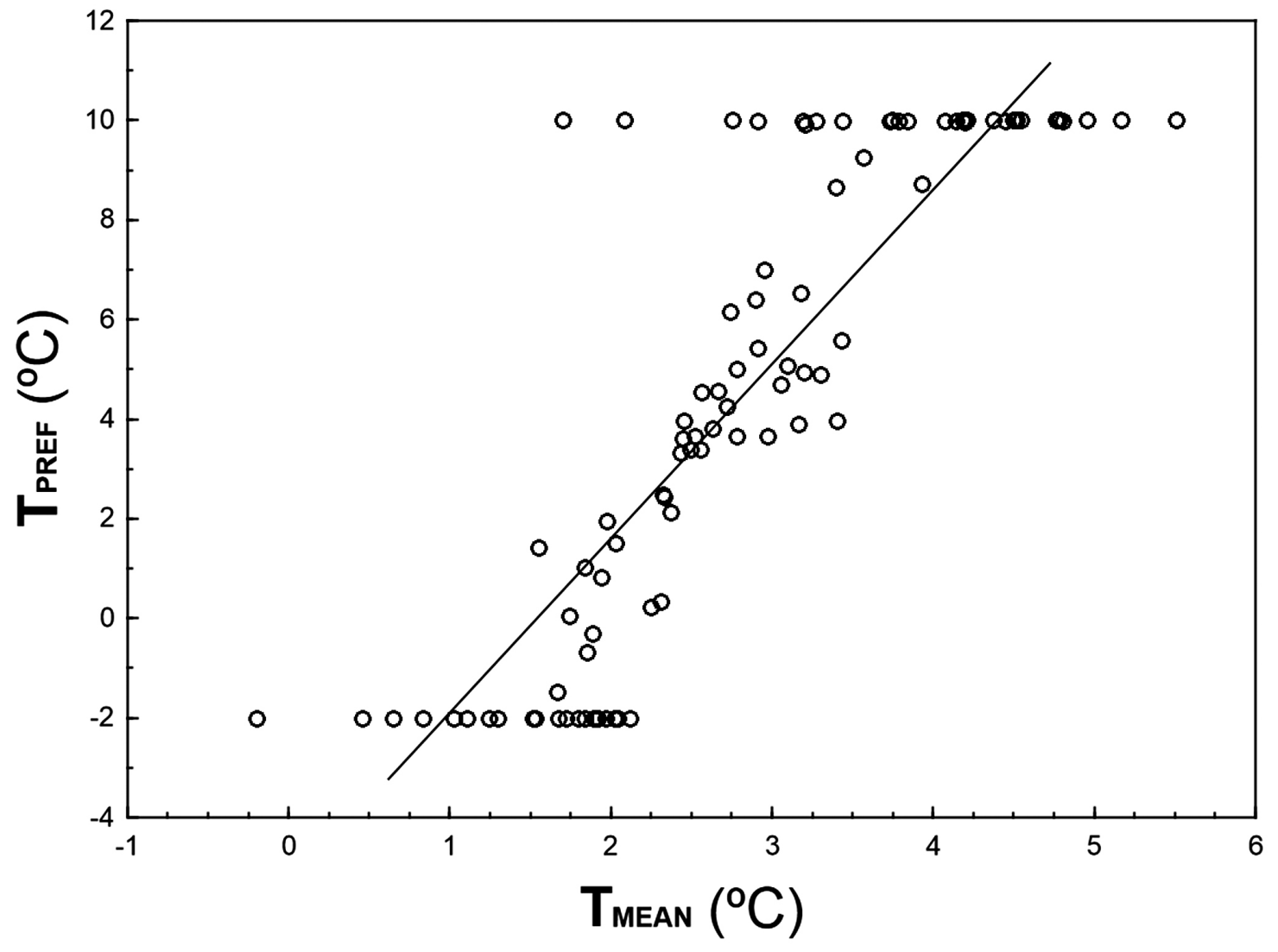




\section{Supplemental Information}

505 Supplemental Text S1. Description of the Spanish Bird Atlas of Winter Birds.

506 Supplemental Code and Data S2. Script for R environment employed in analyses and dataset

507 including four example species.

508 Supplemental Table S3. Parameters defining the relationship between relative abundance and 509 minimum winter temperature utilized in the study and obtained for 103 terrestrial bird species 510 wintering in the Iberian Peninsula, corresponding to winter censuses on $168910 \times 10 \mathrm{~km}^{2} \mathrm{UTM}$ 511 (years 2008-2011).

512 